Baines, A. H. J. \& Hollingsworth, D. F. (1955). Proc. Nutr. Soc. 14, 77.

Bransby, E. R. \& Osborne, B. (1953). Brit. F. Nutr. 7, 160.

Clark, F. le G. \& Dunne, A. C. (1955). Ageing in Industry. London: Nuffield Foundation.

Durnin, J. V. G. A. (1956). Proc. Nutr. Soc. 15, 89.

Durnin, J. V. G. A. \& Mikulicic, V. (1956). Quart. F. exp. Physiol. 41, 442.

FAO: Committee on Calorie Requirements. (1957). F.A.O. nutr. Stud. no. 15 .

Morgan, A. F. (1959). Bull. Calif. agric. Exp. Sta. no. 769.

National Research Council: Food and Nutrition Board. (1958). Publ. nat. Res. Coun., Wash., no. 589.

Norris, A. H., Shock, N. W. \& Yiengst, M. J. (I953). Circulation, 8, 52 I.

Norris, A. H., Shock, N. W. \& Yiengst, M. J. (1955). F. Geront. 10, I 45.

Pyke, M., Holmes, S., Harrison, R. \& Chamberlain, K. (1947). Lancet, 253, 46r.

Shock, N. W. (1951). A Classified Bibliography of Gerontology and Geriatrics. Stanford, California: Stanford University Press.

Shock, N. W. (1957). A Classified Bibliography of Gerontology and Geriatrics. Suppl. I. I949-1955. Stanford, California: Stanford University Press.

\title{
Nutrition and the elderly: Chairman's closing remarks
}

\author{
By R. E. Tunbridge, Department of Medicine, \\ The General Infirmary, Leeds
}

Professor Garry, in opening the discussion, referred to the importance of both nature and nurture in the study of man. Much of the discussion has been devoted to the problem of obesity and to the calorie requirements of the elderly. The frailty of the elderly stressed by Dr Boucher, particularly after the age of 70 when movement becomes limited, and secondary factors, strained resources, both financial and domestic, unsuitable housing and loneliness, all predispose to malnutrition. The difficulties of making a satisfactory dietary survey of the feeding habits of a sample population, let alone one amongst the elderly, were stressed. Miss Hollingsworth mentioned the tendency for the households studied to alter their feeding habits during the period of study as one such difficulty. Many elderly people lead physically restricted lives because of frailty and infirmity and in consequence have lessened energy requirements. Furthermore they are disinclined to bother with cooking so that they frequently only have a light breakfast, a cooked midday meal, and something later in the day. These facts are often forgotten when planning diets for the elderly. All the evidence submitted has indicated the need for a new assessment of the detailed requirements of the elderly and for the formulation of a national food policy. Mrs Newman commented critically on the present position on the lack of food knowledge amongst the public in general and on the difficulties of getting across a sound policy. The President's promise that the matter would be taken up by the Society has been enthusiastically received and fully justified the inclusion of the symposium in the Society's programme.

The hazards of obesity have been r epeatedly stressed,but the lack of agreement as to energy requirements for the elderly was in part due to wide individual variations. An earlier recommendation of FAO that a diminution in the calorie allowance of $7 \%$ for each decade after 25 years should form the basis of calculating calorie 
requirements has recently been modified. Though relevant information is still inadequate the second FAO report on calorie requirements (FAO: Second Committee on Calorie Requirements, r957) suggests, for the decades 25 to 35 years and 35 to 45 years, a decline for each decade by only $3 \%$ of the requirements at 25 . For the decades 45-55 and 55-65 the previous recommendation of a uniform decrement of 7.5\% should be retained. On this basis, requirements at 45 and 65 are 6 and $21 \%$, respectively, less than at 25 . In the decade $65-75$ years a further decrement of $10 \%$ of the requirement at 25 seems justifiable. Information on requirements beyond the age of 75 is lacking but no further decrement is recommended. The changing pattern of life as regards exercise is important and there is increasing evidence that the energy expenditure of the average adult now varies little between the ages of 30 and 60 . Attention to the excess intake of calories needs therefore to be directed to middle life or the pre-elderly phase.

Animal studies, as mentioned by Dr Comfort, have shown in a wide range of insects, fish and animals, that the effect of underfeeding the young is to delay the onset of maturity and to prolong the life span. The Society has had the pleasure of welcoming Professor Nikitin of the U.S.S.R. and hearing of his similar findings. Conversely, overfeeding or excessive feeding tended to a shortening of the life-span and enhanced the liability to certain diseases. Animal studies have indicated not only the importance of diet but also of individual variation and of genetic factors in relation to longevity, and also in the predisposition to tumour formation, kidney disease, blood disorders and lung infection in animals.

The increasing expectation of life at birth in man with the corresponding higher proportion of the population reaching 60 and 70 has altered the pattern of disease. It is now accepted that hypertension has a genetic basis, as has the predisposition to diabetes mellitus. There is a familial basis in hypercholesterolaemia, in Pick's and Altzheimer's disease, and a genetic basis for certain enzyme defects. Therefore diet may have specific as well as general effects, and with increasing knowledge it may be possible to prevent or delay the onset of certain diseases now known to cause considerable morbidity during the second half of life. The rate of development of tumours can already be modified in certain animal species by means of diet. Le Gros Clark, in the discussion, asked if there was any evidence that diet might have a positive effect, that is to say that the addition of certain foodstuffs might increase one's resistence to an infection or prevent conditions such as baldness or muscular weakness. There is suggestive evidence from animal studies that such results may be achieved but so far we have no reliable evidence on this point in man.

The changing pattern of social life and the lack of exercise have been constantly referred to and, whatever the final view as to the aetiology of coronary thrombosis, the importance of lack of exercise as a contributory factor would seem to have been established. Preventive measures must be emphasized and in this respect the attention to dentition and to constipation are important. A defective dentition, whether the outcome of malformation or of unsuitable diet or mal-fitting dentures, can be a major factor in determining the feeding habits of the elderly, particularly in their 
avoidance of meat. Constipation frequently dominates the life of the elderly and there is real need for research into the prevention of this dysfunction.

McCay was able to eradicate many of the defects of the diet in elderly patients in a mental hospital and later in a part of the State of New York by the use of a special flour containing non-fat milk solids, soya flour and wheat germ. An early introduction of a similar flour in Great Britain would go far to solve many of the immediate nutritional problems of the elderly and might be considered by the committee the President proposes to set up to study the nutritional requirements of the elderly. The ultimate solution is dependent upon a fuller understanding of needs and the acceptance by the population as a whole of better nutritional standards.

The clinical evidence has suggested that the existence of gross nutritional deficiency is not a common occurrence today apart from amongst the frail, the chronic sick, and vagrants. The complexity of the clinical problem was well illustrated by Dr Woodford Williams when she stressed the constant occurrence of multiple disorders in the elderly, frequently silent in so far as symptoms were concerned, and the influence one upon another of these diseases in producing the final clinical picture. The complexity of nutritional disorders in this respect was illustrated by $\mathrm{Dr}$ Nordin in his report of a study of senile osteoporosis with his suggestion that it is probably a deficiency disease and by Dr Earl in his study of some clinical effects of the absence of members of the B-complex vitamins; particularly the fact that although the deficiency may be cured biochemically, damage from the initial defect remains and the patient retains his or her disability. The tendency to diminution of gastric secretion and the increasing prevalence of diverticulosis with age, are two more examples of such changes quite apart from the impact of disease processes which may modify the clinical pattern. Today's symposium has drawn attention to the existence of nutritional problems amongst the elderly. It may be necessary to define the terms - the elderly today might be referred to as those between the ages of 60 and $70+$ and those over the age of 75 as the senescents--but whatever classification is agreed, problems cannot be confined to one age group since the dietary habits of previous decades may influence the health of later years. 